\title{
THE CREATIVE USES OF FACEBOOK AS A TOOL FOR ARTISTIC COLLABORATION
}

\author{
Dr Sophy Smith \\ Institute of Creative Technologies \\ The Gateway \\ Leicester \\ United Kingdom \\ ssmith05@dmu.ac.uk \\ http://www.ioct.dmu.ac.uk
}

\begin{abstract}
Facebook has established itself as one of the major players in social networking, claiming that it helps members connect and share with the people in their lives. But what if the people you want to connect and share with are your artistic collaborators? Can Facebook be used creatively, as a collaborative artistic environment? This paper explores the creative use of Facebook as a tool for creative collaboration and establishes a number of possible models of artistic collaboration using Facebook.
\end{abstract}

\section{INTRODUCTION}

Since its foundation in 2004, Facebook has become a major force in social networking, claiming to give people"...the power to share and make the world more open and connected" [1]. Its success has been unprecedented, allowing millions of members to upload photos, and share links and videos as well as personal information about themselves and their lifestyle preferences. How can these tools be used by artists to connect and share with collaborators? Can Facebook be used creatively, as a collaborative artistic tool or environment?

In Creative Collaboration, John-Steiner cites the work of L.S. Vygotsky [2], who suggests that any construction of knowledge is rooted in the cultural environment from which it develops. For Michael Schrage in Shared Minds [3], the quality and quantity of collaboration often depends on the tools used to facilitate it. So, what new knowledge can grow from online social networks such as Facebook, and how can these social networks affect the nature of artistic collaboration? Online social networking has revolutionised the way we interact and participate in society [4]. Communications technology has developed from a one-to-one model (one sender to one receiver, for example the communications media such as the telephone), to a one-to-many model (one sender to many receivers, for example broadcast media such as the television) and now to a many-to-many model enabled by the new communications technologies such as the internet and mobile telephones [5]. Working together, and then sharing that work has become easier, enabled by these new technologies. In the month of March 2009, over 370 million people were active on the Internet worldwide, each spending just over one hour online for each visit [6]. In the same month, over 17 million people in the UK were Facebook users, $27.47 \%$ of the population [7]. It has been estimated that by 2012 , 600 million people will be logged on to social networking sites [8]. This is not just a youth phenomenon. Between February and March 2009 the number of US members of 
Facebook nearly doubled and the fastest growing demographic on Facebook is women over 55 [9].

Social media has changed old models of computer-based interaction. Web 2.0 creates an "architecture of participation... to deliver rich user experiences" [10] and the social tools available offer to be "powerful platforms for cooperation, collaboration and creativity" [11]. This paper focuses on Facebook, as it is currently the most commonly used social online tool in the UK. Online social tools such as Facebook are becoming increasingly integral in our lives. Whilst the authors cited in this paper question what effect the use of these new online social technologies will have on society as a whole, my question is much more specific - what impact will these new technologies have on artistic collaborative practice?

This paper results from a practical research project carried out by the author in early 2009, whilst undertaking a collaborative performance project Alibi with the live art company Assault Events. This project focused on the creative use of Facebook as a tool for creative collaboration, exploring a number of unique and innovative collaborative approaches to the collective creation of artistic work using the Facebook environment by asking questions relating to both artistic process and practice. How could Facebook support collaboration between artists in different geographic locations and working in different disciplines? How could Facebook be used to create and develop collaborative artistic content? How could Facebook be used to encourage direct public involvement and increase public engagement in arts projects and events?

This paper is intended as a starting point for discussions around the creative use of online social media, establishing a number of possible models of artistic collaboration using Facebook.

\section{How can Facebook support collaboration between artists in different geographical locations and working in different arts disciplines?}

Assault Events is a collaborative live art company, formed by like-minded people who shared the same artistic ideals and vision. However, this ideal is not without its complications - the ideal collaborators are not always in the ideal locations at the ideal time. At the time of Assault Events' Alibi project for example, the six collaborators were located across the UK - from the South to the North of England and across the Irish Sea to Belfast and Derry. In addition, these collaborators worked on other projects in other locations at the same time as participating in the Alibi project. The majority of the collaborators were members of Facebook and the basic function of becoming Facebook 'friends' enabled the collaborators to be in direct contact with each other. Collaborators could be in touch with each other, sharing and developing ideas, both before meeting in person and between devising and rehearsal periods, establishing and building project momentum. Independent of both geographical space and time, collaborators could be in touch with each other whenever was convenient and wherever they were located.

A search of other artistic collaborative groups utilizing Facebook reflects this use of the social tool across geographical locations. 'Muse It - Creative Collaboration' is a Facebook group set up to explore creative collaboration, whose description reads: 
EVA 2009 London Conference 6-8 July

Sophy Smith

Join us if you're looking for new ways to share your work with other artists, get differing points of view, or even if you just want a little affirmation. Please feel free to post and comment... [12]

Contributors to the group span South Africa, North America and the United Kingdom. Although all the sharing and feedback of artistic work is between US-based artists, location is still an issue. A poem posted by a member from Redding, California received feedback 5 and a half hours later by a group member from Belhaven, North Carolina, over 3,000 miles away.

In its ability to host and share a variety of media types, Facebook supports collaboration between artists in different disciplines. As well as providing a means of communication and networking between artists, it also allows artists to share their work in a range of ways; on the Wall (for example sharing of potential project ideas, hyperlinks to films, artist's blogs and websites and commission information), in specific Discussion Topics (for example poems, lyrics and links to music and film clips posted by creators and commented on by other group members), though Links (for example to MySpace pages and artist websites in order to promote work and events), Photos (for example sharing visual art work) and Video (for example sharing film work, show reels and advice and tutorials). Group members can add content in whatever format they feel is most suitable to share their work and are able to discuss it in the same forum. This enhances and supports communication between artists working in different disciplines as it offers an independent, non discipline-specific environment to share a range of work in a range of different ways so each artist can choose the most appropriate method for their work.

\section{How can Facebook help create and develop collaborative artistic content?}

As a tool independent of time and space, that hosts a range of media and facilitates a range of artistic sharing practices, Facebook has the potential to support the process of artistic collaboration. But to what extent could Facebook facilitate and support the creation and development of collaborative artistic content? I suggest that it does so in two ways; firstly, as an environment where work can be shared, commented on and subsequently developed and secondly, by using the tools provided to create rather then merely present artistic content.

Facebook is used by many groups of artists to share and develop work in different ways. Some of these groups are more informal, created to connect artists. Two examples of such groups are the Facebook group 'Creative Collaboration', which describes itself as "... a group for easy access to a bunch of people that share the same interests and that might be helpful to get in contact with sometime in the future" [13] and the Facebook group 'Creative Artists', formed "to link visual artists, graphic designers, illustrators, photographers, fine artists, etc. For collaboration, industry help, insights, and work related stuff' [14]. These types of groups have a number of purposes including self-promotion, networking and the provision of critical feedback. Other groups, whilst informal, are set up with the main purpose of sharing work, for example the Facebook group 'MUSE it - Creative Collaboration', who state, "Please feel free to 
post and comment on lyrics, musical compositions, dance choreography, graphic arts, short stories or any other complete or incomplete creative works" [15]. Most of the work shared in the group is lyrics or poetry, though film and music work is also included. Other Facebook groups, for example 'Collaboration Project Los Angeles' differ. This group is a physical group who meet on a monthly basis to, "bring people together to exchange thoughts, bounce ideas around, organise projects and network with others" [16], but who use Facebook as an online dimension to their physical meetings. By signing up to these groups, members sign up to the groups' shared vision, which John-Steiner regards as crucial for successful collaboration [17].

Some groups use Facebook to create collaborative artistic work, for example the Facebook Group 'Art Collaboration' whose description outlines the collaborative nature of the group:

The general idea *member $1 *$ creates a file with an unfinished drawing, then posts a small gif up. *member $2 *$ decides they want to work on modifying version 1 comp, so they get the original file from *member $1 *$, makes modifications, and posts revisions. And so on... [18]

As part of the Alibi project, I was interested in exploring how Facebook tools could be used to create, rather than merely present and share, artistic content.

Some work around the idea of using Facebook to create content has been carried out by students at the University of California, Santa Barbara as part of their undergraduate course, 'Cross-Disciplinary Models of Literary Interpretation'. Students were asked to choose a literary work and treat it according to research paradigms prevalent in other disciplines, resulting in a project entitled Romeo and Juliet : A Facebook Tragedy [19]. The students working on the assignment had carried out a practical research project to explore how Facebook could be used to adapt Shakespeare's play Romeo and Juliet into a "more interesting, easily accessible form" [20]. The project explored non-linear storytelling and character development, using the tools available on Facebook to make the text more interactive for users. A Facebook profile was created for each character and the profile was completed to reflect that character. On a linked group called 'The Streets of Verona', the message board was used to instigate a fight between the Montagues and the Capulets, the Wall was used for characters to directly interact with each other and the Photo section enabled characters to comment on staged pictures of events that the group creators regarded as too complex to represent on Facebook any other way. One function of Facebook is to track social relationships and this provided a tools for the users to gain a deeper understanding of the relationships between characters, for example the type of relationship and the nature of their interactions with others. Once this information had been inputted, the students used the Facebook application Friend Wheel as a tool through which to map character relationships throughout the play.

How could this idea be extended to 'create' character and character relationships rather than merely representing those already created? One idea I began to explore was the way in which character identities could be created and developed using Facebook. 
When devising a new performance piece with Assault Events, the creation and development of characters is a critical part of the devising process. How could Facebook support Assault Events' artistic collaborators to create and develop character and then subsequently explore the relationship between theirs and other characters?

Fraser and Dutta reflect how whilst in the real world the self is presented, in the virtual world it is 'invented' [21]. Online social networking tools have frequently been subject to criticism regarding the way in which they allow deception through enabling individuals to create false or misleading identities. However, for the purpose of creating characters, this same aspect becomes a positive as it can enable the creation and development of artistic content. Parallels between the users creation of alternative identities online has clear parallels with more traditional methods of character creation, for example by playwrights and authors. Fraser and Dutta describe how in the creation and manipulation of online identities on applications such as Facebook, the user has an active role, "like a playwright" [22] and goes on to describe how cyber-sociologists describe this creation of an alternative identity as "writing yourself into being" [23]. The development of characters using Facebook was tried with two characters in Alibi - Joel Carpenter and Velouria Likely. Both collaborators completed a Facebook profile based on their character which they developed themselves including information concerning home town, relationship status, political and religious views, activities and interest, favourite music, TV shows, films, books and photos. This gave collaborators the space and means to develop their own characters, and then when linked as friends, to develop their relationship with the other character.

The provision of tools offered by Facebook reflects the environment and conditions needed for effective creative collaboration in two ways. Firstly, Facebook supports different 'intensities' of interaction between collaborators and different levels of input over the duration of projects, and allows collaborators to move back and forth between working with other and working alone. Facebook can act as an idea repository, logging and retaining ideas and discussions. Secondly, Facebook support different 'types' of interaction and working methods between collaborators. The ability to support different intensities of interaction between collaborators and different levels of input over the duration of projects is crucial for successful collaboration, especially where collaborators and also working on other projects in other places, simultaneously. JohnSteiner regards intensity as essential to creativity [24]. However, Sawyer identifies that a key characteristic of effective creative groups is that innovation happens over time [25]. For distance collaboration to work, collaborators need both intense periods of collaboration as well as times when they can just drop into the process for a shorter period of time. Facebook Groups, independent of time or space, enable members to keep touch with developments whilst not having to contribute continuously.

This ability for collaborators to work on a group project both independently and with others can be important for the successful development of a group creation. Sawyer comments how too much direct group work can result in Production Blocking -group members use so much focus listening closely to other members' ideas they have less mental energy to think of new concepts themselves and the amount of different ideas being produced may distract them from the development of their own. Collaborators 
EVA 2009 London Conference 6-8 July

Sophy Smith

need both time interacting with the group and time alone. One solution Sawyer suggests for Production Blocking is "electronic brainstorming" [26] where ideas are input into a shared computer screen by each member individually, a process that is straightforward using Facebook.

This capacity to input and interact with different levels of intensity during the collaborative process is supported by the repository nature of Facebook. Photos, film, internet links, comments and discussions are all retained and logged and can be accessed for reference or further comment by collaborators at any time from anywhere. This allows groups to practise behaviours that are regarded by Sawyer as key characteristics of effective teams - team members build on the ideas of other collaborators and the actions of individuals only take meaning when they have been developed and integrated into other ideas [27].

How can Facebook be used to encourage involvement and increase public engagements in arts projects and events?

Since 1927, TIME Magazine has chosen a man, woman, or idea that has been most influential in the preceding year. Individuals to receive the distinction have included Adolf Hitler (1938), Elizabeth II (1952), The Computer (1982) and most recently Barack Obama (2008). In 2006, Time Magazine's Person of the Year was awarded to You:

Look at 2006 through a different lens and you'll see another story, one that isn't about conflict or great men. It's a story about community and collaboration on a scale never seen before. It's about the cosmic compendium of knowledge Wikipedia and the million-channel people's network YouTube and the online metropolis MySpace. It's about the many wrestling the power from the few and helping one another for nothing and how that will not only change the world, but also change the way the world changes... Who has that time and that energy and that passion? The answer is, you do. And for seizing the reins of the global media, and for founding and framing the new digital democracy, for working for nothing and beating the pros at their own games, Time's Person of the Year for 2006 is you. [28]

Fraser and Dutta describe how in the new century, power has shifted from "top down vertical forms of 'coercion' to horizontal systems of 'cooperation' and 'collaboration ', [29]. Similarly, Tapscott refers to the Net Generation (the first generation to be "growing up digital" [30]) as, "the 'collaboration and relationship' generation" [31], bringing collaboration to the workplace, marketplace and social spaces [32]. For the Net Generation, the internet is no longer another information repository but is somewhere for sharing and collaboration [33]. With computers becoming both faster and cheaper, financial and technological barriers have been lowered and more and more people are accessing and participating in social networking. Shirky reflects that now large-scale coordination is achievable at a low cost (both in terms of time and money), the cost of co-operation and collective action has also fallen, making it easier for people to take part in group activities online [34]. Through Facebook, artists can harness this public 
desire to cooperate and collaborate, engaging the public in projects and events both through raising awareness of specific artists or projects, enabling and encouraging creative participation in arts projects.

Tapscott identifies that $70 \%$ of the Net Generation like to feel part of a knowledgeable and exclusive group and want to work with companies to improve goods and services [35]. Arts companies and individual artists are using Facebook groups as another mechanism through which to engage with their public, who become members of their groups. 'Pilot Theatre' for example (whose Facebook group currently has 490 members), use their group to promote and communicate their work to group members [36], posting company news, directing members to related websites, twitter feeds etc. and posting photos and video clips of the company's work. Motionhouse Dance Theatre, The Royal Ballet, the Royal Opera House and the Tate Modern are all also represented on Facebook, though group sizes range from 93 to over 16,000. Facebook enables arts organisations, groups and individuals to advertise their events either free through creating and publicising an event to fans or members of the group or by paying for an advert on Facebook. Facebook advertising allows individuals and groups to create an advert directly targeted at members within a specific age group, geographical location, educational level, relationship status or interest group, making a marketing strategy potentially much more effective.

According to Tapscott, $90 \%$ of the Net Generation in the UK add or change things online on a regular basis [37]. Web 2.0 technologies have led to an explosion in the amount of User Generated Content, which is created then shared within groups with similar areas of interest. Such groups (for example those on Flickr or Facebook), that come together with the purpose of sharing skills for improvement are described by the sociologist Etienne Wenger as a "community of practice" [38]. Within these online communities, members participate on different levels, groups exhibiting what Shirky describes as a "power law distribution" [39]. The number of members making up the community is not the same as the number of contributors. Shirky describes how the most active contributors are far more active than the second most active, and both in turn are more active than most of the rest [40].

\section{CONCLUSION}

Shirky reflects that although social technologies do not create the desire for collective action, they do increase any existing need for it whilst simultaneously removing obstacles to it [41]. These new technologies have resulted in new social behaviours, which are being reflected in artistic practice. For a wide section of society, online social technologies such as Facebook have become a part of daily life. Artists, as a section of that wider society, are beginning to use these online social tools as part of their creative process and in some cases the creative product. As Shirky reflects, the important question is no longer whether the use of these tools will spread and reshape society, but how they will do so [42]. This paper aimed to raise some questions about how the use of online tools may impact on artistic collaborative practice both in terms of the artist, and their audience. 
EVA 2009 London Conference 6-8 July

Sophy Smith

What is evident from researching into the use of Facebook as a tool for artistic collaboration is that the different artistic groups that use Facebook have different models of online collaboration, depending on their specific needs. However, it is possible to determine a number of characteristics and potential uses. Facebook's independence of space and time enables it to support collaboration between artists working across different geographical locations and in different time frames. Facebook enables collaborative teams to create an online environment where collaborators can meet to share and develop ideas without having to physically interact. Collaborators can contribute whenever they can from wherever they are and are able to input and interact with different levels of intensity over a period of time. The use of Facebook during the Alibi project provided Assault Events with the tools to create an online creative environment that could be accessed 24 hours a day from any location. Collaborators could either to work alone or together and were able to share work and ideas, leave video clips and pictures, play music, ask questions and chat, providing many of the benefits of a physical studio but without the costs and complications of getting collaborators together in one place at a certain time. In its provision of tools to host and share a range of media, coupled with the use of discussion groups to facilitate communication and understanding between artists, Facebook can support collaboration between artists working in different disciplines.

Whilst it is apparent that Facebook can be also used to create and develop artistic content as well as encouraging direct public involvement and increasing public engagement in arts projects and events, what is particularly interesting is that, to date, the creative uses of Facebook have been split mostly down amateur/professional lines. Generally, it tends to be informal amateur groups that form online groups to share and develop work or to meet other collaborators, whereas professional groups use Facebook in a more formal manner, to share information 'about' their work online. Facebook and other online social tools offer more than merely providing other ways for collaborative artists and arts organisations to promote their work with a larger audience. Although Facebook does offer new ways to engage new audiences through an increased online profile it, more importantly, offers the potential to actively involve the audience through collaboration in the creative process. As Fraser and Dutta comment cultural production is the one sphere where the distinction between amateur and professional is the hardest to defend [43], especially I would suggest in Web 2.0 online environments, where User Generated Content is prolific. As I commented in the introduction, this paper was intended as a starting point for my research into the potential creative use of Facebook as a tool for artistic collaboration. From here I intend to develop this work, collaborating with the live art company Assault Events on a specific piece of online collaborative work. This project will use Facebook and other online social tools to create a specific piece of collaborative work, which whilst being initiated by the company allows the public to be engaged as creative collaborators, suggesting, commenting on and developing creative content.

Online social technologies enable collaborators to make artistic work differently and in doing so may also change the nature of their practice. Currently, the majority of arts groups using Facebook continue with their existing working practices, but in a new 
environment. However, these new online social environments offer exciting possibilities to change the nature of the practice itself. Facebook and other online social tools can enable arts collaborators the facilities and tools not just to do what they are already doing in a different way, but also to do new things in new ways.

\section{References}

[1] FACEBOOK. Facebook Group. http://www.facebook.com/home.php? ref=home\#/facebook?ref=pf [accessed May 28 2009]

[2] JOHN-STEINER, V. Creative collaboration. Oxford University Press, 2000, p.5.

[3] SHRAGE, M. Shared minds: the new technologies of collaboration. Random House. 2000.

[4] FRASER, M AND DUTTA S. Throwing sheep in the boardroom. John Wiley and Sons Ltd, 2008. p.ix.

[5] SHIRKY, C. Here comes everybody. Penguin Books, 2009. p.87.

[6] NIELSON ONLINE. Global Index Chart. 26 May 2009. http://www.nielsenonline.com/resources.jsp?section $=$ pr_netv [accessed May 26, 2009]

[7] NIELSON ONLINE. United Kingdom : top 10 parent companies. 26 May 2009. http://www.nielsen-online.com/resources.jsp?section=pr netv [accessed May 26, 2009]

[8] FRASER, M. and DUTTA, S. Throwing sheep in the boardroom. John Wiley and Sons Ltd, 2008. p.6.

[9] INSIDEFACEBOOK.COM Number of US Facebook users over 35 nearly doubles in last 60 days. 25 March 2009. http://www.insidefacebook.com/2009/03/25/number-of-us-facebook-users-over35-nearly-doubles-in-last-60-days/ [accessed May 26, 2009]

[10] O'REILLY, Tim. Web 2.0 : compact definition? 1 Oct 2005. http://radar.oreilly.com/archives/2005/10/web-20-compact-definition.html [accessed May 28, 2009]

[11] FRASER, M. and DUTTA, S. Throwing sheep in the boardroom. John Wiley and Sons Ltd, 2008, p.278.

[12] MUSE IT - CREATIVE COLLABORATION FACEBOOK GROUP. http://www.facebook.com/s.php?ref=search\&init=q\&q=MUSE \%20it\&sid=fac5330d1123affd0984087427832004\#/group.php? $\underline{\text { sid }=\text { fac5330d1123affd0984087427832004\&gid }=34482301484 \& \text { ref }=\text { search }}$ [accessed May 12, 2009]

[13] CREATIVE COLLABORATION FACEBOOK GROUP. http://www.facebook.com/home.php\#/group.php? $\underline{\text { sid }=35 \mathrm{ce} 71 \mathrm{ff} 74546 \mathrm{fff} 0 \mathrm{~b} 201 \mathrm{~b} 4 \mathrm{bcc} 2 \mathrm{f} 28 \mathrm{c} 5 \mathrm{\& gid}=23048066788 \& \mathrm{ref}=\text { search }}$ [accessed May 5, 2009] 
EVA 2009 London Conference 6-8 July

Sophy Smith

[14] CREATIVE ARTISTS GROUP FACEBOOK GROUP.

http://www.facebook.com/s.php?q=creative + artists + group $\& n=-$

$1 \& \mathrm{k}=400000000010 \& \mathrm{sf}=\mathrm{r} \& \mathrm{init}=\mathrm{q} \& \mathrm{sid}=7 \mathrm{ee} 42505 \mathrm{ef} 74 \mathrm{e} 5579 \mathrm{ce} 2697 \mathrm{f} 2 \mathrm{ede} 80 \mathrm{f} 5 \mathrm{\# l}$

group.php?

$\underline{\text { sid }=7 \text { ee42505ef74e5579ce2697f2ede80f5\&gid }=53578934168 \& \text { ref }=\text { search }}$

[accessed May 5, 2009]

[15] MUSE IT - CREATIVE COLLABORATION FACEBOOK GROUP.

http://www.facebook.com/s.php?ref=search\&init=q\&q=MUSE

\%20it\&sid=fac5330d1123affd0984087427832004\#/group.php?

$\underline{\text { sid=fac5330d1123affd0984087427832004\&gid }=34482301484 \& \text { ref }=\text { search }}$

[accessed May 12, 2009]

[16] COLLABORATION PROJECT LOS ANGELES FACEBOOK GROUP. http:// www.facebook.com/s.php? ref $=$ search\&init $=$ q\&q $=$ MUSE

\%20it\&sid=fac5330d1123affd0984087427832004\#/group.php?

$\underline{\text { sid }=17 \mathrm{a} 6 \mathrm{fba} 8134 \mathrm{fdcedaeaa} 20507 \mathrm{bd} 950 \mathrm{~d} 0 \& \mathrm{gid}=29447061790 \& \mathrm{ref}=\text { search }}$

[accessed May 5, 2009]

[17] JOHN-STEINER, V. Creative collaboration. Oxford University Press, 2000. p.64.

[18] ART COLLABORATION FACEBOOK GROUP.

http://www.facebook.com/group.php?

$\underline{\text { sid }=35 \mathrm{ce} 71 \mathrm{ff} 74546 \mathrm{fff} 0 \mathrm{~b} 201 \mathrm{~b} 4 \mathrm{bcc} 2 \mathrm{f} 28 \mathrm{c} 5 \& \mathrm{gid}=23048066788 \& \mathrm{ref}=\text { search } \# / \text { grou }}$ p.php?

$\underline{\text { sid }=57 \mathrm{~d} 70 \mathrm{e} 4 \mathrm{~d} 8 \mathrm{c} 3 \mathrm{a} 1 \mathrm{bf} 23 \mathrm{~b} 980 \mathrm{ee} 5 \mathrm{e} 5 \mathrm{~b} 85 \mathrm{~b} 71 \& \mathrm{gid}=5083919869 \& \mathrm{ref}=\text { search }}$ [accessed May 5, 2009]

[19] SKURA, H, NIERLE, K and GIN, G. "Romeo and Juliet: A Facebook Tragedy." http://english149-w2008.pbworks.com/Romeo-and-Juliet:-A-Facebook-Tragedy [accessed Nov 11, 2008]

[20] Ibid.

[21] FRASER, M. and DUTTA, S. Throwing sheep in the boardroom. John Wiley and Sons Ltd, 2008. p.40.

[22] Ibid, p.32.

[23] Ibid, p.40.

[24] JOHN-STEINER, V. Creative collaboration. Oxford University Press, 2000. p.83.

[25] SAWYER, K. Group genius. Basic Books, 2008. p.14.

[26] Ibid, p.65.

[27] Ibid, p.15.

[28] GROSSMAN, L. Time's Person of the Year : You. 13 December 2006. http://www.time.com/time/magazine/article/0,9171,1569514,00.html [accessed May 28, 2009]

[29] FRASER, M. and DUTTA S. Throwing sheep in the boardroom. John Wiley and Sons Ltd, 2008. p.206.

[30] TAPSCOTT, D. Grown up digital. McGraw-Hill, 2009. p.2.

[31] Ibid, p.35. 
[32] Ibid, p.89.

[33] Ibid, p.40.

[34] SHIRKY, C. Here comes everybody. Penguin Books, 2009. p.47.

[35] TAPSCOTT, D. Grown up digital. McGraw-Hill, 2009, p.190.

[36] Pilot Theatre Facebook Group. http://www.facebook.com/group.php? $\underline{\text { sid }=35 \mathrm{ce} 71 \mathrm{ff} 74546 \mathrm{fff} 0 \mathrm{~b} 201 \mathrm{~b} 4 \mathrm{bcc} 2 \mathrm{f} 28 \mathrm{c} 5 \& \mathrm{gid}=23048066788 \& \mathrm{ref}=\mathrm{search} \# / \mathrm{grou}}$ p.php? $\underline{\text { sid }=544469 \mathrm{ddc} 1022 \mathrm{e} 90 \mathrm{e} 38 \mathrm{~d} 036421 \mathrm{e} 6 \mathrm{~d} 06 \mathrm{e} \& \mathrm{gid}=2399299650 \& \mathrm{ref}=\text { search }}$ [accessed May 5, 2009]

[37] TAPSCOTT, D. Grown up digital. McGraw-Hill, 2009. p.54.

[38] SHIRKY, C. Here comes everybody. Penguin Books, 2009. p.100.

[39] Ibid, p.123.

[40] Ibid, p.124.

[41] Ibid, p.159.

[42] Ibid, p.308.

[43] FRASER, M. and DUTTA, S. Throwing sheep in the boardroom. John Wiley and Sons Ltd, 2008. p.126. 